Article

\title{
Inter-Correlation among the Hydrophilic-Lipophilic Balance, Surfactant System, Viscosity, Particle Size, and Stability of Candelilla Wax-Based Dispersions
}

\author{
Martina Lindner ${ }^{1,2, *,+} \mathbb{C}$, Magdalena Bäumler ${ }^{2,+}$ and Andreas Stäbler ${ }^{2}$ \\ 1 TUM School of Life Sciences Weihenstephan, Technical University of Munich, Weihenstephaner Steig 22, \\ 85354 Freising, Germany \\ 2 Fraunhofer-Institute for Process Engineering and Packaging IVV, Giggenhauser Strasse 35, \\ 85354 Freising, Germany; magdalena.baeumler@ivv.fraunhofer.de (M.B.); \\ andreas.staebler@ivv.fraunhofer.de (A.S.) \\ * Correspondence: martina.lindner@ivv.fraunhofer.de; Tel.: +49-8161-491-536 \\ + These authors contributed equally to this work.
}

Received: 22 October 2018; Accepted: 14 December 2018; Published: 19 December 2018

\begin{abstract}
Owing to a decrease in mineral oil resources, it is crucial to develop packaging materials based on renewable resources. Hence, a water vapor-barrier coating is developed as a natural wax-based dispersion. This dispersion should be stable over the storage time. In this study, the physical stability of a wax-based melt dispersion was analyzed ( $24 \mathrm{~h}$ and 21 days after production), and instability phenomena such as agglomeration, coalescence, and flotation were identified. Furthermore, the inter-correlations among the particle size, viscosity of the continuous phase, physical stability, surfactant chemistry, and hydrophilic-lipophilic balance value were characterized. Particle sizes were described by volume/surface mean $d_{3,2}$, volume moment mean $d_{4,3}$, and number mean $d_{1,0}$ diameter, as well as the span of the volume and number distribution. Stability was characterized by the flotation rate, emulsion stability index, and Turbiscan stability index. Coalescence and agglomeration were not observed after the solidification of the wax particles. A significant correlation was observed for the emulsion stability index, with $d_{3,2}$, and for flotation rate, with $d_{1,0}, d_{4,3}$, and viscosity as well, with $d_{1,0}, d_{3,2}$. Surfactants with hydrophilic-lipophilic balance values of 11-13.5 seem to be the most suitable for stabilizing candelilla wax-in-water suspensions. Particles were smaller, and wax suspensions were better stabilized using Tween 20 and Span 20, compared with Tween 80 and Span 80 .
\end{abstract}

Keywords: melt dispersion; suspension; emulsifiying stability index (ESI); Turbiscan stability index (TSI); hydrophilic-lipophilic balance (HLB); particle size distribution; Turbiscan

\section{Introduction}

Melt emulsification is a well-known process for producing suspensions, wherein the solid phase is melted and emulsified as a dispersion of droplets in the continuous phase. Melted particles are disintegrated by mechanical energy input, e.g., via diagonal blade stirrers, in a heated stirring tank. By cooling the system, the droplets solidify as spheres, and the hot emulsion changes into a suspension with a solid dispersed phase [1]. This method is predominantly used for lipid dispersed phases, and has the advantage of not requiring organic solvents [2].

This study is motivated by the development of a natural wax-based dispersion coating for packaging materials. Owing to the decrease in mineral oil resources, fossil oil-based packaging is raising concerns. Hence, the need for bio-based and biodegradable packaging materials has increased. Packaging materials require suitable oxygen and water vapor barriers. Coatings containing starch [3-9] 
and proteins [10-14] provide a good barrier toward oxygen, whereas hydrophobic materials such as waxes and lipids are suitable barriers against water vapor. Wax has already been used as an edible coating [15-18] and a paper coating [19], and it has been incorporated into biopolymers for increasing the water vapor barrier $[19,20]$. In the present study, wax was applied as a wet chemical dispersion coating. Therefore, candelilla wax is dispersed in water with the use of $10 \%$ emulsifying agent, and this suspension is subsequently applied onto a polymer layer. During heat drying, the water in the suspension is evaporated before the wax particles melt, creating a homogenous layer [21]. The applicability of dispersions as coatings depends, among others, on the following parameters [21,22]:

- Particle size: small particle sizes with a narrow distribution are required; hence, particles are evenly molten after curing. Non-molten particles induce cracks and compromise the water vapor barrier;

- Suspension stability: a slow flotation process is required, which ideally exceeds the storage time of the dispersion.

However, the particle size and the stability are affected by different parameters, of which quite a few have already been examined (Table 1). To the authors' knowledge, so far, no publication is available, which especially analyzes the inter-dependencies between different parameters such as the hydrophilic-lipophilic balance (HLB) system, viscosity, and particle size distribution, and their final effect on dispersion stability. Therefore, the aim of this study was to identify and improve the understanding of these parameters.

In general, the stability of melt emulsions can be divided into two stages: first, the liquid droplets must be stabilized in the emulsion (emulsion stability) to prevent coalescence [23]; second, after the dispersed wax droplets are solidified, the suspension stability is influenced by phase separation (flotation) and changes in particle size distribution (aggregation and/or Ostwald ripening) (Figure 1).

In the first part of this study (cf. Section 3.1), the effect of the continuous phase viscosity on the particle size and on the phase separation was investigated. Additionally, the impact of the particle size on the phase separation was examined. In the second part of this study (cf. Section 3.2), how different emulsifier systems and HLB affect these factors are additionally evaluated. In the last part (cf. Section 3.3) the long-term stability of the suspension is examined.

Table 1. Literature overview of the direct and indirect parameters affecting the stability of dispersions. (HLB = Hydrophilic-Lipophilic Balance).

\begin{tabular}{ccc}
\hline Effect of Parameters & On & Literature \\
\hline particle size & phase separation & {$[24]$} \\
viscosity of continuous phase & particle size distribution & phase separation 1 \\
viscosity of continuous phase & piscosity of continuous phase & {$[25,26]$} \\
HLB value & particle size distribution & {$[27]$} \\
HLB value & phase separation & - \\
HLB value & viscosity of continuous phase & {$[28-32]$} \\
emulsifier system & particle size distribution ${ }^{1}$ & {$[33]$} \\
emulsifier system & phase separation 1 & - \\
emulsifier system & change in particle size distribution & {$[34,35]$} \\
HLB value & over storage time 1 & {$[36]$} \\
stirring intensity, time, and speed & particle size & {$[24,36,37]$} \\
mixing temperature & particle size & {$[35,38,39]$} \\
phase concentration & particle size & {$[35,38,39]$} \\
surfactant concentration & particle size & {$[20,30,35,39-42]$} \\
aggregation state of the disperse phase & particle size & {$[30,33,35,36,38,43]$} \\
phase concentration & phase separation & {$[44,45]$} \\
& & {$[46]$}
\end{tabular}




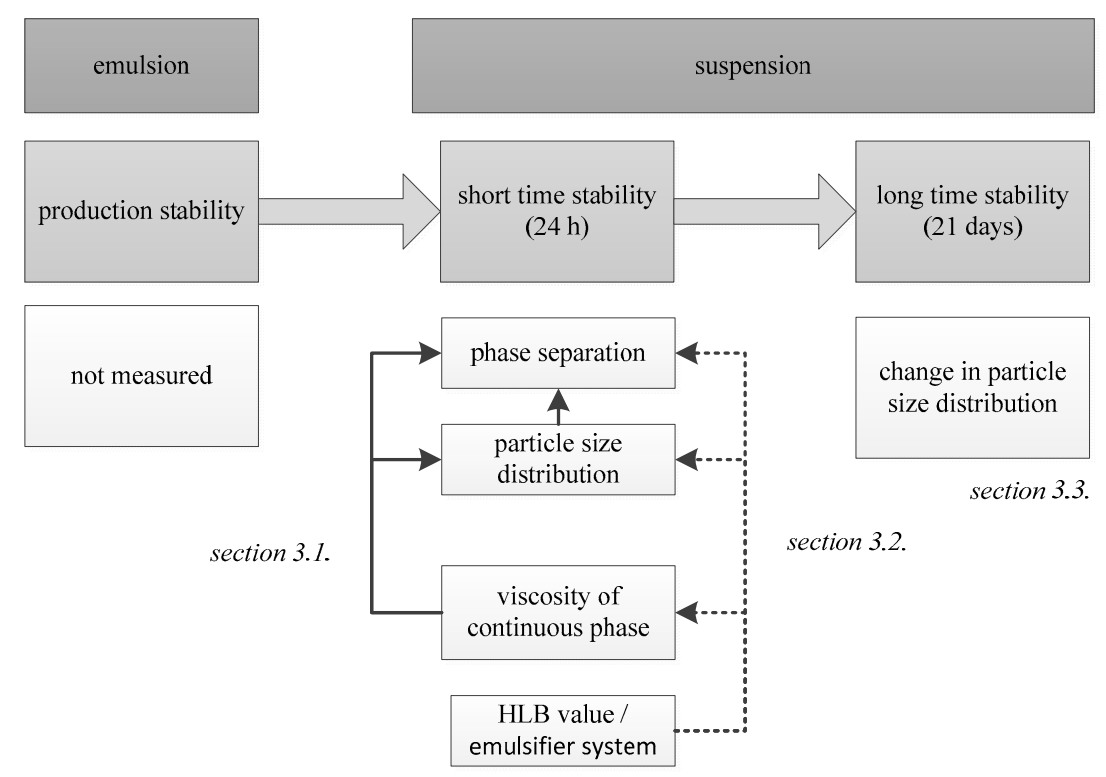

Figure 1. Processes decreasing the short- and long-term stabilities of melt emulsions.

\section{Materials and Methods}

\subsection{Materials}

Candelilla wax (melting point $72{ }^{\circ} \mathrm{C}$ ) was purchased from KahlWax (Trittau, Germany). Emulsifying agents (Span 20, Tween 20, Span 80, Tween 80) were purchased from Sigma-Aldrich (Steinheim, Germany).

\subsection{Melt Emulsification}

For producing the emulsion, an emulsifier concentration that is higher than the critical micelle concentration (CMC) should be used. A concentration that is lower than the CMC would affect the results, as the particle size is then mainly determined by the availability of the emulsifying molecules. Thus, the concentration should be above the CMC (that means, that even after the disintegration of wax into particles, enough emulsifying molecules should be available to form micelles). From an estimation that can be found in the Section 1 in Supplementary Materials, it can be assumed that emulsifier contents of $>5 \%$ would not determine the particle size due, to the non-availability of the emulsifier molecules (see Figure S1). This is why we used an emulsifier concentration of $10 \%$ in relation to the wax content, to be well above the minimum concentration of $5 \%$.

For preparing wax suspensions, $100 \mathrm{~mL}$ of deionized water containing $2.5 \mathrm{~g}$ of surfactants was tempered at $85^{\circ} \mathrm{C}$. Next, $25 \mathrm{~g}$ of candelilla wax was added for melting, and the mixture was stirred at a constant rate or $230 \mathrm{rpm}$ for $3 \mathrm{~min}$ in a double-walled reactor. After melting, the hot suspensions were dispersed in an Ultra-Turrax T25 system (IKA-Werke, Staufen im Breisgau, Germany) at 11,000 rpm for $3 \mathrm{~min}$. The wax suspensions were stirred at a constant rate of $230 \mathrm{rpm}$ in the double-walled reactor until room temperature was reached.

Mixtures of Tween 20 (HLB 16.5) and Span 20 (HLB 8.6) (blends referred to as T2S2), as well as blends of Tween 80 (HLB 15) and Span 80 (HLB 4.3) (blends referred to as T8S8) were used as emulsifying agents. For adjusting HLB values between 9 and 16.5, the mixing ratio was calculated according to the following equations, with $X$ being the target HLB value:

$$
\begin{gathered}
\%(\text { span })=\frac{\left(X-\mathrm{HLB}_{\text {span }}\right) \times 100}{\mathrm{HLB}_{\text {tween }}-\mathrm{HLB}_{\text {span }}} \\
\%(\text { tween })=100 \%-\%(\text { span })
\end{gathered}
$$




\subsection{Suspension Stability}

Based on Stokes' Equation (Equation (3)), three main factors affect the flotation velocity ( $v_{\text {Stokes }}$ ) of the dispersion [47]: differences in density between the continuous $\left(\varrho_{\mathrm{L}}\right)$ and discontinuous $\left(\varrho_{\mathrm{S}}\right)$ phases, viscosity $(\eta)$, and particle size $\left(r_{\mathrm{S}}\right)$. The latter one is in turn affected by agglomeration:

$$
v_{\text {Stokes }}=9 / 2 \cdot g \cdot r_{S}^{2} / \eta \cdot\left(\rho_{S}-\rho_{L}\right)
$$

In literature, this is characterized by the amount of sediment or floating material after different storage times [33], the stability index (SI) [40], or the transmission and backscattering of light through two phases [26,48-54].

In this study, the stability of the wax suspensions was measured at $25{ }^{\circ} \mathrm{C}$ using Turbiscan Lab (Formulaction, L'Union, France) with the associated software TurbiSoft (Formulaction, version 2.0, France). This instrument determines the temporal local backscattering signal (BS) at $880 \mathrm{~nm}$ for the dispersions stored in a vial, whereby the intensity of the scattered light depends on the size and concentration of dispersed particles. Thus, the changes in the particle size (coalescence or agglomeration) and/or local changes in the particle concentration (sedimentation/flotation) are detected under actual storage conditions. One scan was conducted every $15 \mathrm{~min}$ during the first three hours after production, and then every $60 \mathrm{~min}$ during the next $23 \mathrm{~h}$. For examining the appearance of Ostwald ripening or agglomeration over the storage time, the dispersions were measured on days 0 , $1,2,7$ and 21. For comparing the stabilities of different suspensions, the flotation layer thickness as well as the Turbiscan stability index (TSI) and flotation rate $v$ of each suspension were calculated by a software program. TSI is a parameter that considers all of the destabilization processes occurring in the sample cell. The parameter was developed by Formulaction, and is calculated by TurbiSoft based on BS measurements. The flotation rate was calculated by TurbiSoft using the phase limit migration of the flotation layer at a threshold of $\triangle \mathrm{BS}=-3 \%$. A high stability is demonstrated by a low TSI value.

By using the flotation layer thickness, emulsion stability index (ESI) was calculated according to the equation given by Mirhosseini et al. [55] from Equation (4), wherein HE is the initial height of the suspension, HC is the flotation layer height after $24 \mathrm{~h}$, and HS is the sedimentation layer height after $24 \mathrm{~h}$. A high stability is demonstrated by a large ESI value.

$$
\operatorname{ESI}(\%)=\frac{\mathrm{HE}-(\mathrm{HC}+\mathrm{HS})}{\mathrm{HE}} \times 100 \%
$$

\subsection{Particle Size Distribution}

Particle size distribution was determined on days $0,1,2,7$, and 21 by laser diffraction analysis, using a Mastersizer 3000 (Malvern Instruments, Malvern, UK). Before measurements, the samples were re-dispersed in the Mastersizer instrument for $2 \mathrm{~min}$ at $3000 \mathrm{~min}^{-1}$. The Sauter diameter $d_{3,2}$, De Brouckere diameter $d_{4,3}$, and the number mean diameter $d_{1,0}$ were estimated during measurements. Furthermore, the widths of the volume and number distribution, referred to as $\operatorname{span}(v)$ and $\operatorname{span}(n)$, respectively, were used as parameters for the polydispersity of the collective particles. span was calculated from Equation (5), wherein $D_{50}$ is the median, with $50 \%$ of the particles in the distribution having a smaller diameter than it. $D_{90}$ and $D_{10}$ describe the diameters for which $10 \%$ and $90 \%$ of the distribution have a smaller particle diameter than them, respectively. The index $(x)$ represents the application on either the volume distribution $(v)$ or the number distribution $(n)$.

$$
\operatorname{span}(x)=\frac{D_{50}(x)}{D_{90}(x)-D_{10}(x)}
$$

Typically, $d_{3,2}$ describes the average ratio between the volume and surface area. The lower the particle sphericity, the higher the surface area at a constant volume, i.e., $d_{3,2}$ decreases [56]. By comparison, $d_{4,3}$ is more susceptible to large particles. The differences between all these mean 
diameters decrease with the increasing uniformity of the particle sizes. All the diameters are equal only for a completely monodisperse distribution [57].

Using one parameter for describing bulk materials is a simple approach for comparing different samples. However, owing to the different particle sizes and shapes, the loss of information encountered is large when using only one mean diameter. Therefore, particle sizes are described by volume/surface mean $d_{3,2}$, volume moment mean $d_{4,3}$, and number mean $d_{1,0}$ diameter, as well as the span of the volume and number distribution in the following section.

\subsection{Dynamic Viscosity}

For measuring the dynamic viscosity of the continuous phase, $1.25 \mathrm{~g}$ of surfactant was dissolved in $50 \mathrm{~mL}$ of deionized water in an ultrasonic bath (Sonorex Digitec DT 31, Bandelin, Germany) for $5 \mathrm{~min}$. The dynamic viscosity of this solution was measured using a Bohlin CVO 100 rheometer (Bohlin Instruments, Pforzheim, Germany) at a constant shear rate of $250 \mathrm{~min}^{-1}$ at $25^{\circ} \mathrm{C}$. In addition, the dynamic viscosities of all pure emulsifying agents were separately measured.

\subsection{Scanning Electron Microscope (SEM)}

Samples were prepared by gold sputtering. Images were acquired using a JSM-7200F scanning electron microscope (JEOL, Tokyo, Japan) at $0.5 \mathrm{kV}$. The working distance was maintained at $10 \mathrm{~mm}$.

\subsection{Analysis of Wax Composition}

The composition of the candelilla wax was analyzed using a gas chromatography system 7890A (Agilent Technologies, Santa Clara, CA, USA) equipped with a flame ionization detector (Agilent Technologies, USA), a Zebron ZB-5HT capillary GC column $(30 \mathrm{~m} \times 0.25 \mathrm{~mm} \times 0.1 \mu \mathrm{m}$, Phenomenex, Torrance, CA, USA), and an autosampler (Agilent Technologies, USA). The system operated with $1.5 \mathrm{~mL} \cdot \mathrm{min}^{-1}$ carrier gas flow (helium) and a split-ratio of 1:50. The following temperature conditions were used for analysis: $50^{\circ} \mathrm{C}(0.5 \mathrm{~min}), 50-200{ }^{\circ} \mathrm{C}\left(40^{\circ} \mathrm{C} \cdot \mathrm{min}^{-1}, 4.25 \mathrm{~min}\right), 220-340^{\circ} \mathrm{C}\left(5^{\circ} \mathrm{C}, 24 \mathrm{~min}\right)$, $340^{\circ} \mathrm{C}$ (15 min). A total of $10 \mathrm{mg}$ candelilla wax was dissolved in $20 \mathrm{~mL}$ dichloromethane. A lupeol reference standard ( $\geq 94 \%$, Sigma-Aldrich) and an alkane standard solution C21-C40 (40 mg. $\mathrm{L}^{-1}$ each, in toluene, Sigma-Aldrich) were used for quantification.

\subsection{Statistical Analysis}

The wax suspensions were produced in duplicate. The particle size distribution of each suspension was measured threefold, and stability was measured in triplicate. Viscosity was determined in duplicate, each with 15 data points. Differences in the results for the surfactant blends or the HLB values were statistically examined using the analysis of variance (ANOVA) and the Tukey honestly significant difference (HSD) test, or in the case of heteroscedastic data, the Kruskal-Wallis test was employed in addition to Dunn's test at a significance level of $p \leq 0.05$. Bartlett's test was performed prior to analyses, to confirm the assumption of homoscedasticity at a significance level of $p \leq 0.05$. The correlation was examined using Spearman's correlation test at a significance level of $p \leq 0.05$.

\section{Results and Discussion}

\subsection{Short Time Stability: Interaction between Particle Size, Phase Separation, and Viscosity of the Continuous Phase}

The correlations among the phase separation, particle size, and viscosity were examined for an immense statistical population, including dispersions produced by using HLB values of between 9 and 15. HLB values were obtained by using the T2S2 and T8S8 systems. Table 2 shows the correlations obtained between stability, viscosity, and particle sizes. Ranges of the measured values are provided in the first column and first row. One exemplary measurement result using the Turbiscan Lab is shown graphically in Figure S2, in the Supplementary Materials. 
Table 2. Results obtained for Spearman's correlation between the parameters of the particle size distribution of the dispersed phase (Sauter diameter $d_{3,2}$, De Brouckere diameter $d_{4,3}$, and the number mean diameter $d_{1,0}$ ); parameters of suspension stability (Turbiscan stability index (TSI), emulsion stability index (ESI), flotation rate $v$ ); and viscosity of the continuous phase. Positive correlation $(p<0.05$, Spearman's rank correlation coefficient $>0)$ is marked by " + ", negative correlation $(p<0.05$, Spearman's rank correlation coefficient $<0)$ is marked by "-", no significant correlation is marked by “0” ( $p>0.05)$.

\begin{tabular}{ccccc}
\hline Parameters & $\begin{array}{c}d_{\mathbf{1}, 0} \\
\mathbf{( 0 . 1 6 - 2 . 7 2} \boldsymbol{\mu m})\end{array}$ & $\begin{array}{c}d_{3,2} \\
\mathbf{( 2 . 1 1 - 9 . 2 7} \boldsymbol{\mu m})\end{array}$ & $\begin{array}{c}d_{4,3} \\
\mathbf{( 3 8 . 9 8 - 2 1 3 . 6 3} \boldsymbol{\mu m})\end{array}$ & $\begin{array}{c}\text { Viscosity } \\
\mathbf{( 1 . 9 5 - 2 . 7 2} \mathbf{~ m P a} \cdot \mathbf{s})\end{array}$ \\
\hline Viscosity $(1.95-2.72 \mathrm{mPa} \cdot \mathrm{s})$ & - & - & 0 & 0 \\
ESI $(3.53-34.04 \%)$ & 0 & 0 & 0 & 0 \\
TSI $(2.40-12.30 \%)$ & 0 & 0 & 0 & - \\
$v\left(0.20-31.86 \mathrm{~mm} \cdot \mathrm{h}^{-1}\right)$ & + & 0 & + & + \\
\hline
\end{tabular}

\subsubsection{Effect of Continuous Phase Viscosity on Particle Size}

The viscosity of the continuous phase exhibited a significant, albeit weakly negative, monotonic relation with $d_{1,0}$ (see Table 2). This means that a higher viscosity leads to a lower $d_{1,0}$. Similarly, Wooster, et al. [58] reported that the droplet size decreases with an increasing viscosity of the continuous phase by the addition of polyethylene glycol in an oil-in-water $(\mathrm{O} / \mathrm{W})$ emulsion. As reported by Köhler and Schuchmann [59], a high viscosity for the emulsion leads to a decrease in the conveyor effect, which in turn increases the retention time in the dispersion zone and leads to a high energy input, thus decreasing $d_{1,0}$.

Qian and McClements [35] stated that two additional phenomena potentially occur with the increase in the viscosity of the continuous phase: (i) a decrease in the droplet collision frequency, whereby the droplet re-coalescence decreases; and (ii) a decrease in the surfactant adsorption rate, whereby the droplet re-coalescence increases (in this case, re-coalescence refers to coalescence a short time after emulsion preparation, and not to coalescence after a long storage time, such as 21 days). The relevant phenomenon significantly depends on the specific system [35]. As $d_{4,3}$, which is a value that is considerably reasonable for large particles [60], and which may possibly appear because of coalescence, was not affected, the aforementioned effect (ii) can be excluded.

With increasing viscosity, $d_{3,2}$ decreased. This result implies that the ratio between volume and surface area decreases, suggesting that particles become less spherical, and thus, their surface area increases.

\subsubsection{Effect of Particle Size on Phase Separation}

The correlation of the particle size with stability is discussed in the following sequence using ESI, TSI, and flotation rate (see Table 2).

The ESI, and thus the flotation layer height, is affected by the packing density of the flotation layer; the particle size distribution, and the interparticle and external forces (e.g., gravitational force) [61]. According to literature, three predominant effects could occur:

- Without any interactions between particles, monodisperse spheres form a layer with a dense structure. For hexagonal close packing, the maximum theoretical volume fraction to be attained is $74 \%$ [62]. Cases with negligible interparticle interactions between small particles typically lead to the formation of a thin flotation layer, because the unit cell of the structure is small (Figure 2a,b);

- With decreasing particle size, the surface/weight ratio increases; thus, the impact of the interaction forces increases. Typically, gravitational force dominates the interparticle forces for larger particles $(>50 \mu \mathrm{m})$ [61]. Hence, larger particles do not agglomerate, whereas smaller particles flocculate if the attractive forces (i.e., Van der Waals force) dominate over the repulsive forces (i.e., electrostatic force) [63]. During particle agglomeration, the gap between the agglomerates and other particles 
increases. Thus, the particles form a thick flotation layer, and the volume density of the layer decreases [61,63] (Figure 2c).

- High degrees of polydispersity can lead to a dense layer with a high volume fraction, as small particles fill the gaps among large particles [61] (Figure 2d).

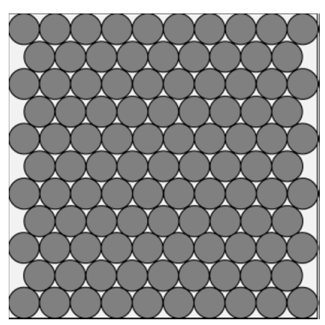

(a)

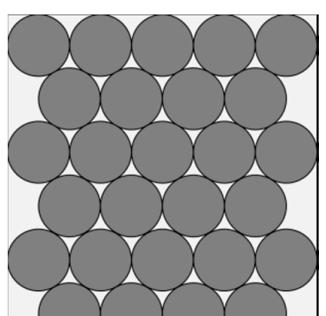

(b)

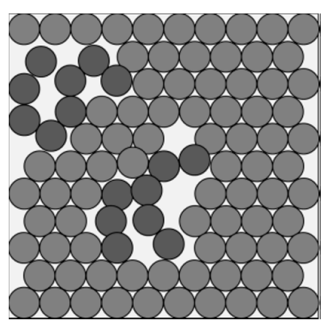

(c)

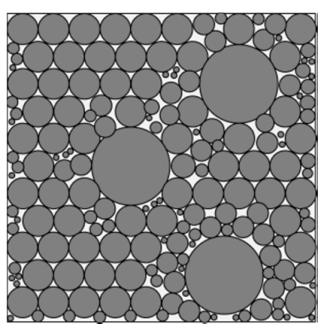

(d)

Figure 2. (a) Smaller particles with a surface density of $88 \%$; (b) larger particles with a surface density of $78 \%$; (c) flocculation with a surface density of $82 \%$; (d) polydispersity with a surface density of $90 \%$.

Although a correlation between the number mean diameter $d_{1,0}$ and the ESI, i.e., flotation layer height, was expected, in line with the abovementioned explanation, such an effect was not observed.

However, a correlation between $d_{3,2}$ and the ESI was observed. As $d_{3,2}$ describes the particle volume in relation to the particle surface area, a decrease in the value for $d_{3,2}$ suggested an increase in the surface area, i.e., reduced particle sphericity (see Figure 3). The decrease in $d_{3,2}$, i.e., a decrease in sphericity, was expected to lead to a less dense degree of packing, thereby to a thick flotation layer, and finally to a low ESI (positive relationship). However, the Spearman correlation revealed a significantly moderate negative relationship between $d_{3,2}$ and the ESI. One possible explanation for this result was that reduced sphericity exerted similar effects as polydispersity (Figure 2d).

$d_{4,3}$ for large particles was reasonable; therefore, a negative correlation between $d_{4,3}$ and the ESI is expected (cf. Figure 2d), but is not proven statistically.

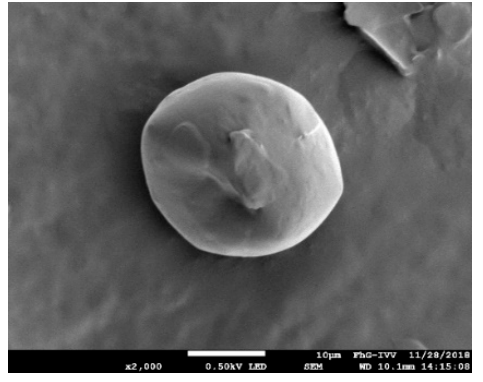

(a)

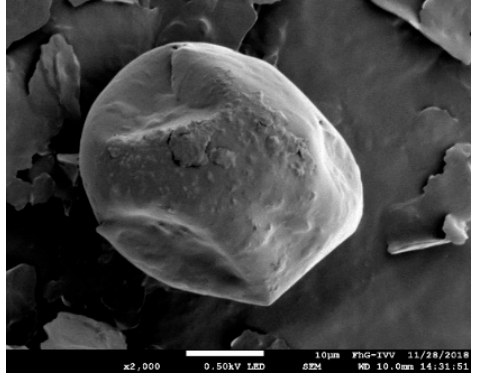

(b)

Figure 3. Exemplary scanning electron microscope (SEM) images from spherical and less spherical particles: (a) high spericity particle; (b) low sphericity particle.

Several studies have reported correlations among sedimentation, flotation, and TSI [26,48-50]. In this study, this correlation was not verified, possibly because TSI was a calculated parameter that was affected by various factors, including flotation, sedimentation, and agglomeration. Unfortunately, the exact algorithm used for the calculation in this software package has not been published. Therefore, this value should be carefully dealt with, and at best, only used when the different processes occurring in the dispersion are well known.

Corresponding to Stokes' law [46], larger particles float more rapidly than smaller ones, which was observed for $d_{1,0}$ and $d_{4,3}$, implying a moderate monotonic positive correlation to the flotation rate (despite the simplified assumptions by Stokes, which were further developed [64-66]). Apparently, an 
opposite effect for extremely small particles promoting the agglomerate formation, and thus, flotation rate increase [67], was not observed. This result was not in agreement with those stated in Section 3.3.

Salas [68] has provided an overview of the correction factors that relate the particle shape with velocity. However, the surface area mean diameter $d_{3,2}$, i.e., sphericity, did not exhibit any correlation with the particle velocity.

\subsubsection{Effect of Continuous Phase Viscosity on Phase Separation}

In agreement with Stokes' law, the particle velocity depends, among other factors, on the dynamic viscosity of the continuous phase [46]. With increasing viscosity, the particles ascend slowly; thus, the physical stability of the suspension is improved [59]. In agreement with this background, a strong negative correlation between the viscosity and flotation rate $(v)$ was observed.

However, neither a relationship between the viscosity and ESI, nor that between viscosity and TSI was observed. TSI has been already reviewed critically in the previous section. The missing correlation with the ESI might be explained by the fact that the ESI was measured after $24 \mathrm{~h}$. After $24 \mathrm{~h}$, the flotation velocity converged to zero. Therefore, flotation is assumed to be mainly completed. Thus, at this time, the flotation layer height considerably depends on the amount and arrangement of particles, and not on the viscosity of the continuous phase.

\subsection{Short Time Stability: Effect of Surfactants}

Griffin [29] has reported that the surfactant is the most effective when the HLB values for the surfactant and dispersed phase are the same. Hou et al. [38] suggested that to first identify the most suitable HLB value, the HLB value must be varied via the blending of surfactants, as blends typically work better than single surfactants [25]. Next, the most appropriate chemical structure should be defined by maintaining a constant HLB value, albeit by varying the surfactant type. Remington and Beringer [69] have proposed an HLB value of between 10 and 16 for wax-in-water suspensions. More precisely, an optimal HLB value of between 14 and 15 for candelilla wax has been reported [28,70,71].

\subsubsection{Effect of the HLB Value}

Besides the chemical type of the emulsifying agent, the balance between the size and strength of the hydrophilic and lipophilic groups of the surfactant molecule is equally important for the particle size and stability of emulsions [31,72]. As mentioned above, the HLB system provides a simple method to describe the strength of the hydrophilic or lipophilic character of an emulsifying agent. The combination of high and low HLB values for surfactants has been reported to achieve better results compared with the use of a single surfactant $[31,38]$. Therefore, different combinations are tested. The particle size and stability of dispersions, which were prepared with T2S2, as well as those of T8S8 blends, were monitored by Mastersizer and Turbiscan. Figure 4 shows the results.

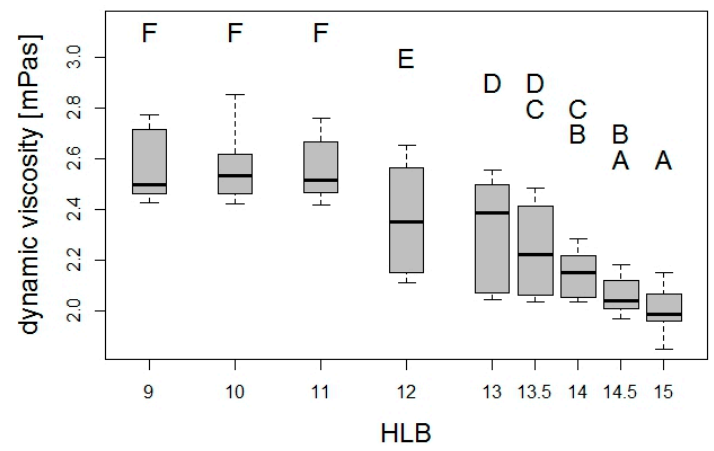

(a)

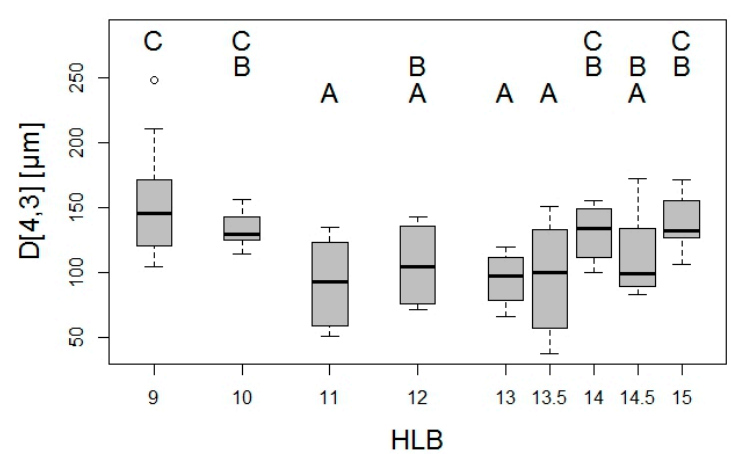

(b)

Figure 4. Cont. 


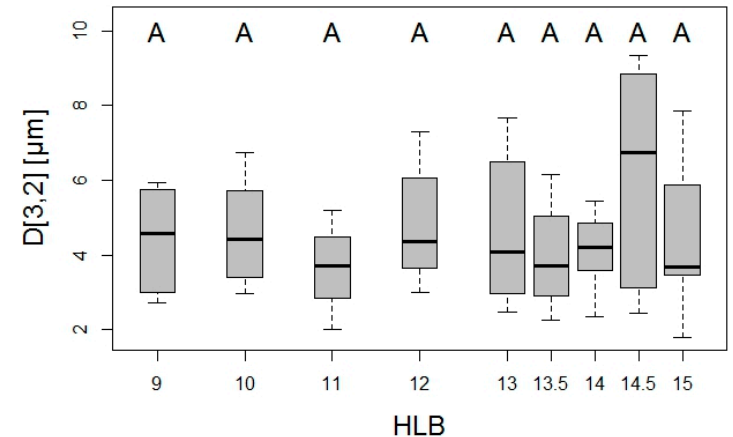

(c)

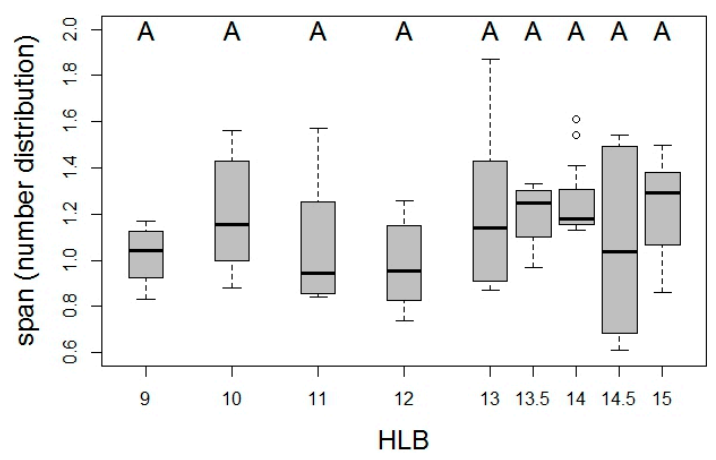

(e)

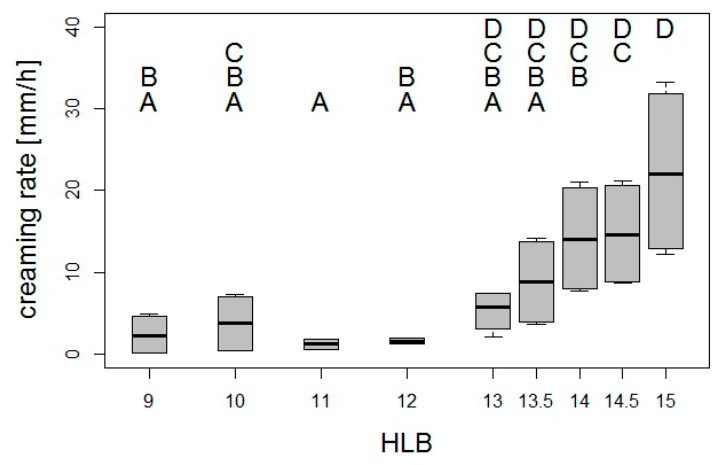

(g)

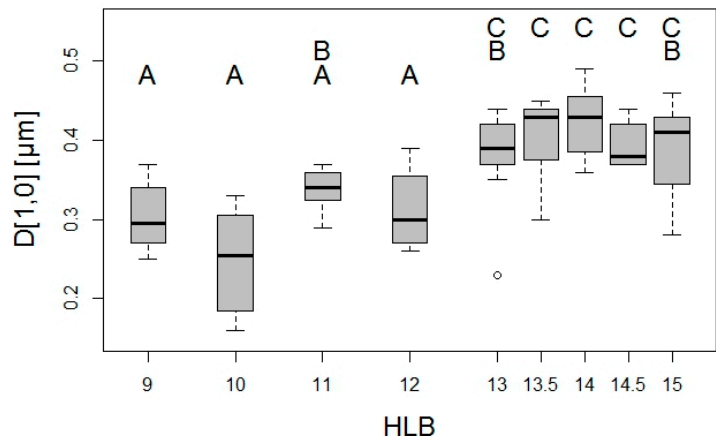

(d)

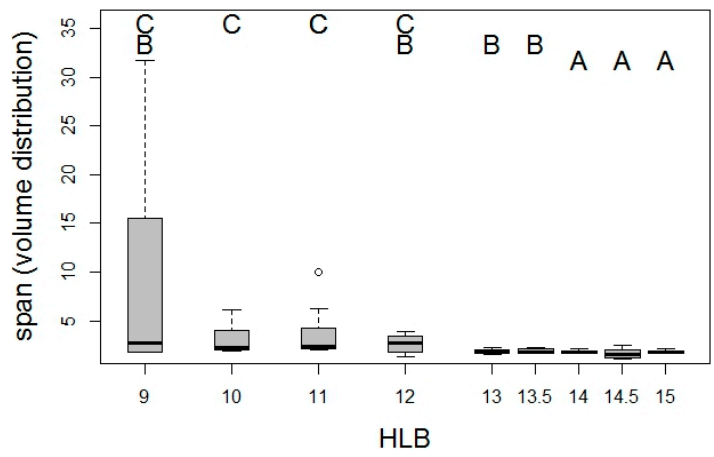

(f)

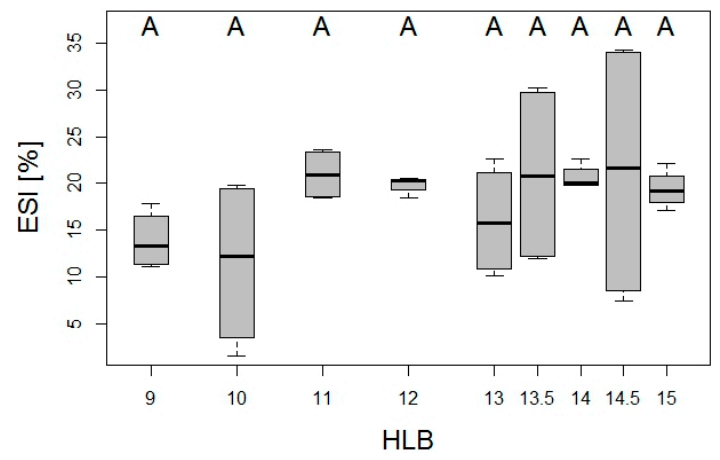

(h)

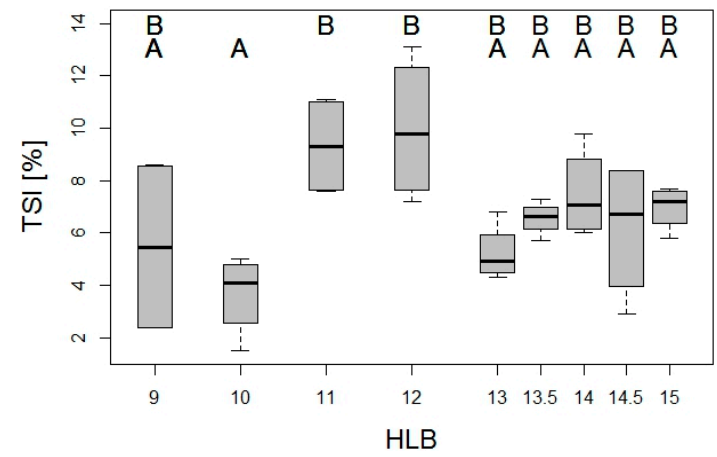

(i)

Figure 4. Effect of the surfactant blend on the (a) dynamic viscosity of the continuous phase, (b) volume-weighted moment mean diameter $d_{4,3}$, (c) surface area mean diameter $d_{3,2}$, (d) number mean diameter $d_{1,0}$, (e) span of the number distribution, (f) span of the volume distribution, (g) flotation rate of the wax particles, (h) emulsion stability index (ESI), and (i) Turbiscan stability index (TSI). Note: Letters above represent post hoc test results, and different letters represent different statistical groups (Tukey honestly significant difference (HSD) or Dunn's test, $p<0.05$ ). 
Viscosity

The results shown in Figure 4a revealed the highest viscosity $(\sim 2.5 \mathrm{mPa} \cdot \mathrm{s})$ of the continuous phase for low HLB values of 9-11. With the decrease in the HLB value, the concentration of highly the viscous Span surfactant increased, whereas the concentration of the less viscous Tween decreased (cf. Table 3).

Table 3. Dynamic viscosity $\eta$ of pure emulsifying agents and water (here: the continuous phase) at $25^{\circ} \mathrm{C}$ at a constant shear rate of $100 \mathrm{~s}^{-1}$.

\begin{tabular}{|c|c|c|c|}
\hline Substances & HLB & Molecular Weight $\left(\mathrm{g} \cdot \mathrm{mol}^{-1}\right)$ & $\eta(\mathrm{mPa} \cdot \mathrm{s})$ \\
\hline Tween 20 & 16.7 & 1227 & $396 \pm 7$ \\
\hline Span 20 & 8.6 & 346 & $3476 \pm 63$ \\
\hline Tween 80 & 15 & 1310 & $455 \pm 72$ \\
\hline Span 80 & 4.3 & 428 & $1000 \pm 14$ \\
\hline Water & - & - & $0.890^{1}$ \\
\hline
\end{tabular}

\section{Particle Size}

$d_{4,3}$ was significantly affected by HLB values, and ranged from $\sim 100$ to $\sim 150 \mu \mathrm{m}$ (Figure $4 \mathrm{~b}$ ). Ohba [74] has reported an HLB value of 14.5 for candelilla wax. Hence, the minimum particle size is expected to have an HLB of 14.5. One explanation for this deviation was probably the determination method for the HLB value, which was carried out by using mineral oil as the continuous phase in [74]. A second explanation might be the origin of candellila wax. As candellila wax is a natural product, its composition can undergo facile changes, due to climatic and soil conditions, for example [75-79]. All of the obtained sources were in agreement with the results of this study, where the main n-alkane was C31 (cf. Table 4). However, the percentages of the diverse fractions were different (see Table S1). The composition of the wax used in the present study is as follows:

Table 4. Composition of candelilla wax used in this study. Analysis was performed with gas chromatography; original data are shown in Figure S3.

\begin{tabular}{cc}
\hline Substance & Amount \\
\hline alkane C23 & $0.01 \%$ \\
alkane C24 & $0.02 \%$ \\
alkane C25 & $0.03 \%$ \\
alkane C26 & $0.05 \%$ \\
alkane C27 & $0.09 \%$ \\
alkane C28 & $0.20 \%$ \\
alkane C29 & $2.11 \%$ \\
alkane C30 & $0.56 \%$ \\
alkane C31 & $30.06 \%$ \\
alkane C32 & $0.67 \%$ \\
alkane C33 & $3.83 \%$ \\
alkane C34 & $0.07 \%$ \\
alkane C35 & $0.38 \%$ \\
lupeol & $0.83 \%$ \\
\hline
\end{tabular}

In contrast to $d_{4,3}, d_{3,2}$, i.e., the sphericity, was not affected by the HLB value (Figure $4 \mathrm{c}$ ). $d_{1,0}$ was apparently more greatly affected by the HLB value (Figure 4d), which can possibly be explained by the impact of the viscosity: As the HLB value affected the viscosity (c.f. Figure 4a) and the viscosity correlated with $d_{1,0}$, the HLB value was also expected to correlate with $d_{1,0}$.

Typically, the number distribution was rather affected by small particles, whereas the volume distribution was more affected by isolated large particles [60]. On the other hand, the span of the 
number distribution did not exhibit any relation to the HLB value (Figure 4e), and the span of the volume distribution (Figure 4f) revealed a low degree of polydispersity by the use of high HLB values ( $>12)$. Such a high HLB value led to a low coalescence rate (during production, when the wax is liquid) and a low polydispersity. The following processes might be overlapped in this observation, with the two latter values being dominant:

- High HLB values $(>10)$ led to a low viscosity. The low viscosity of the continuous phase led to an increased droplet collision frequency. Therefore, droplet re-coalescence increases with high HLB values [35];

- High HLB $(>12)$ values were achieved via the incorporation of an additional tween agent, which has a high molecular weight, possibly leading to a low critical packing parameter (CPP) [11,38]. Thus, the amount of the absorbed surfactant molecules on the surface of the wax particles should be low for high HLB values. Hence, a high HLB value possibly increases re-coalescence;

- The high water solubility of the surfactant at high HLB values $(>10)$ possibly increased the adsorption rate of surfactant on the wax surface, due to the increased molecular mobility. Hence, a high HLB value possibly decreases re-coalescence;

- The better suitability of HLB values in terms of chemical similarities between the emulsifier and the disperse phase led to better stabilization and prevention of re-coalescence.

Stability

Statistically, the suspensions containing the emulsifying agents with HLB values of between 9 and 13.5 exhibited the lowest flotation rates $\left(\sim 3 \mathrm{~mm} \cdot \mathrm{h}^{-1}\right)$ (Figure $4 \mathrm{~g}$ ). This result is in agreement with those obtained for $d_{4,3}$ (Figure $4 \mathrm{~b}$ ) and the Stokes' law (Equation (3)). Surprisingly, a statistically significant correlation was not obtained between the TSI and the ESI, or between TSI and the HLB values (Figure 4h,i). However, this result was in agreement with those obtained in Section 3.1.2.

In summary, HLB values between 11 and 13.5 afford the lowest $d_{4,3}$, span of the volume distribution, and flotation rate.

\subsubsection{Effect of the Surfactant System and the Molecular Structure}

The emulsifying properties of two sorbitan esters (i.e., Span 20 and Span 80, respectively), each in combination with its corresponding ethoxylate (Tween 20 and Tween 80, respectively), were examined at HLB values of between 9 and 15. The range between 9 and 15 was selected, because it is the range that can be covered by both systems, T2S2 and T8S8, respectively. As shown in Figure 5, the suspensions prepared with T2S2 and T8S8 were compared on the basis of the viscosity of the continuous phase, their particle size, and the resulting physical stability.

Viscosity

The results revealed that T2S2 blends lead to a higher viscosity $(\sim 2.5 \mathrm{mPa} \cdot \mathrm{s})$ of the continuous phase (Figure 5a), which is in agreement with the results obtained in Section 3.1.2. The HLB value of Span 20 was greater than that of Span 80, and the HLB value of Tween 20 was greater than that of Tween 80 . Therefore, compared with T8S8 blends, T2S2 blends contain more of the Span-emulsifying agent, to achieve a certain HLB value. Moreover, the viscosity of Span 20 was greater than those of the four emulsifying substances. Hence, the dynamic viscosity of the T2S2 blends was greater than those of the corresponding T8S8 blends.

\section{Particle Size}

With respect to the particles sizes, T2S2 blends led to significantly smaller $d_{4,3}$ values $(\sim 125 \mu \mathrm{m})$, i.e., less outliers (Figure $5 \mathrm{~b}$ ). For $d_{1,0}$, significant differences were not observed. However, T2S2 particles were less spherical, due to the lower $d_{3,2}(\sim 3.75 \mu \mathrm{m})$. An explanation for these observations is as follows: 


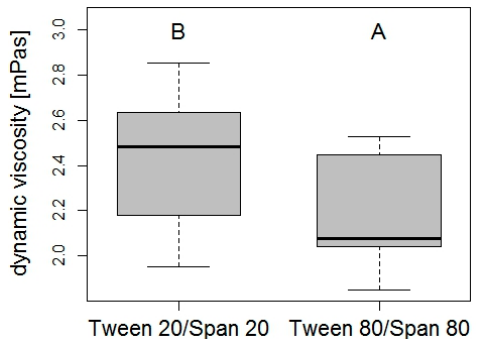

(a)

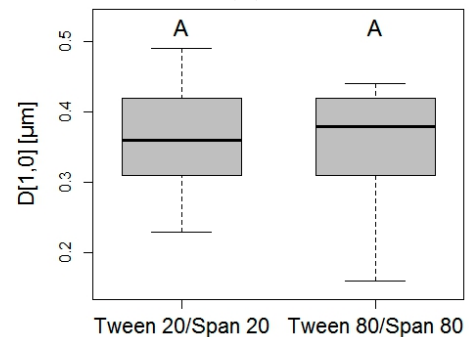

(d)

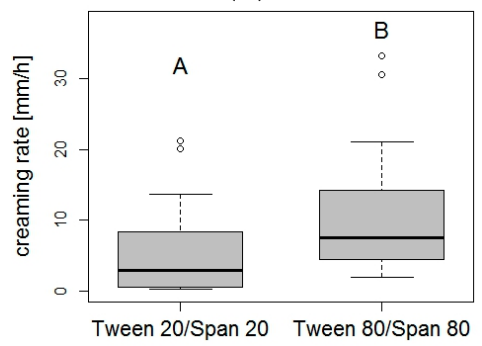

(g)

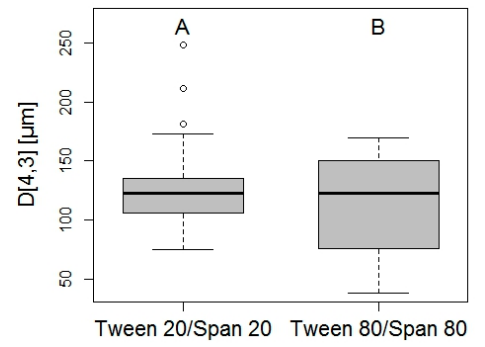

(b)

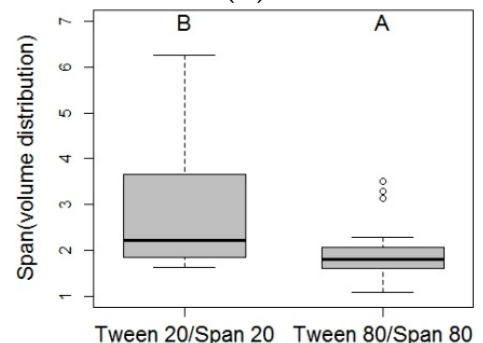

(e)

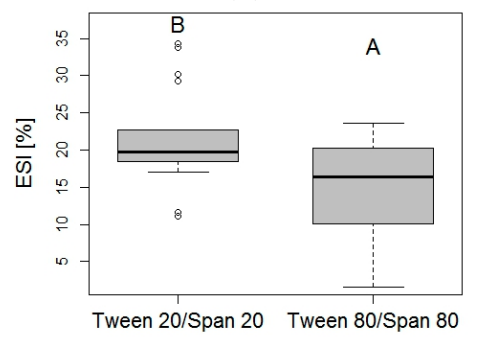

(h)

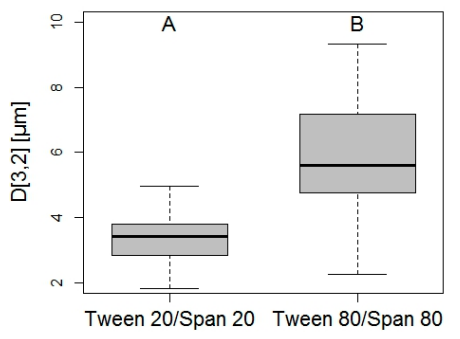

(c)

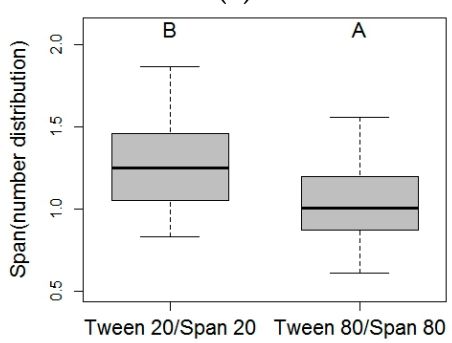

(f)

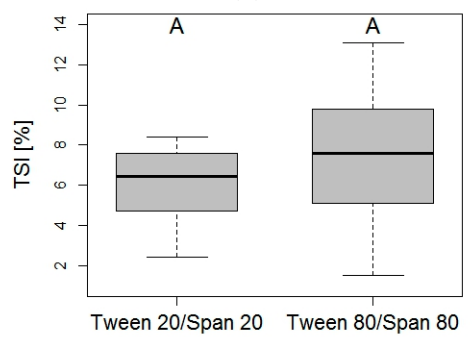

(i)

Figure 5. Effect of the surfactant blend on the (a) dynamic viscosity of the continuous phase, (b) volume-weighted moment mean diameter $d_{4,3}$, (c) surface area mean diameter $d_{3,2}$, (d) number mean diameter $d_{1,0}$, (e) span of the volume distribution, (f) span of the number distribution; (g) flotation rate of the wax particles; (h) ESI, and (i) TSI. Note: Letters above represent post hoc test results, and different letters represent different statistical groups (analysis of variance or Kruskal-Wallis test, $p<0.05$ ).

T2S2 exhibited significantly higher spans of the volume and number distribution (Figure 5e,f). Damodaran, et al. [80] have reported that a high span is related to particle coalescence. As is described in Section 3.3., this effect was excluded as a possible effect of instability after the solidification of the wax particles. Therefore, re-coalescence possibly occurs only during the production of the suspension when the wax is molten. This process is possibly affected by three factors:

Coalescence typically occurs when the film between the droplets is not stable, and it ruptures [81]. Tiller, Yeh, and Leu [63] have reported that the film ruptures with increased stress on the film. The stress increased with the increased effect of interparticle forces, which occurred with a decrease in the particle size [82].

In addition, with the decrease in the particle volume, the total surface area of the dispersed phase, and thus, the interfacial area between wax and water, increased. As the suspensions contained a constant amount of the emulsifying agent, the surfactant film thickness decreased; hence, the stability of the film against ruptures decreased.

This low sphericity (low $\left.d_{3,2}\right)$ possibly led to a high specific surface area, and therefore, to a thinner surfactant film on the particle surface, which ruptures easily.

In summary, the following explanation can be assumed: T2S2 blends lead to smaller particles $\left(d_{4,3}\right)$, which are not spherical $\left(d_{3,2}\right)$ during production, while simultaneously increasing the tendency to coalesce. Similarly, a few large agglomerates were observed, and the span increased. However, the question arises with regard to why the particles were not spherical. A similar result was observed 
in other studies [32,83], wherein HLB was varied and exhibited an optimum value with the smallest particle sizes. These small particles exhibited the lowest sphericities [32], similar to that observed in this study. This was related to the chemical and fluid processes at the phase interface. However, for the present study, no clear explanation can be given based on the gained information.

Another influencing factor during suspension production are the chemical and steric structures of the used surfactants $[28,29,31,84]$. Correspondingly, unsaturated bonds in the dispersed phase were rather attracted by unsaturated chains in the surfactant, and vice versa. Unsaturated bonds were present in Tween 80 and Span 80, whereas completely saturated bonds were present in Tween 20 and Span 20 (Figure 6). Hence, smaller particles with T2S2 blends are probably related to the affinity of saturated alkanes of the candelilla wax for the saturated chains of the surfactant $[75,85]$. In addition, the CPP (i.e., the packing tightness of the surfactant molecules on the wax surface) was greater for smaller molecules and shorter polyoxyethylene chains (Figure 6) $[28,42]$.
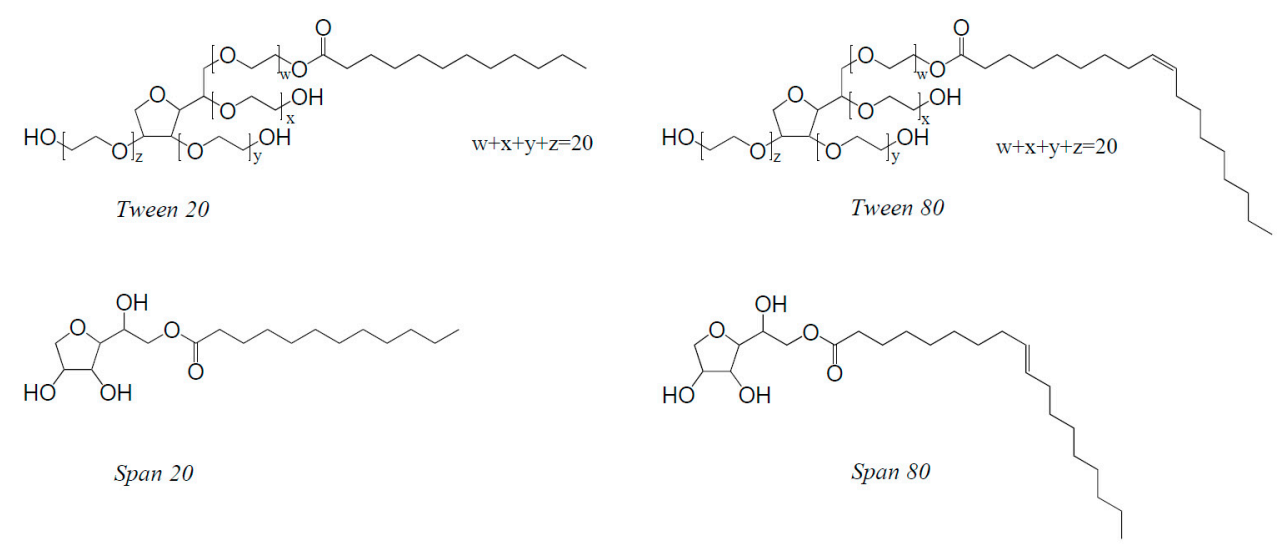

Figure 6. Structural formulae of Tween 20, Span 20, Tween 80, and Span 80.

Stability

T2S2 systems exhibited a lower flotation rate $\left(\sim 3 \mathrm{~mm} \cdot \mathrm{h}^{-1}\right.$, Figure $\left.5 \mathrm{~g}\right)$, which was explained by the higher viscosity of the continuous phase (Figure 5a) [46]. In addition, the ESI was significantly higher (Figure 5h). This result was in accordance with the assumption that T2S2 led to smaller particles and higher degrees of polydispersity (Figure 5e,f). Both of these effects led to a denser layer [61]. In contrast, differences were not observed for the TSI results (Figure 5i).

In summary, the molten wax emulsion was assumed to be better stabilized by using T2S2, and the particles were smaller compared with the use of T8S8.

\subsection{Long-Term Stability: Changes in Particle Size Distribution}

To identify whether agglomeration or coalescence occurs during a storage time of 21 days, Turbiscan measurements were performed after days $0,1,2,7$, and 21. In addition, changes in the particle size over storage time were observed by using the Mastersizer for HLB 13-15. Results are shown graphically in Figures S2 and S3 in the Supplementary Materials.

Agglomeration or coalescence can potentially be monitored by Turbiscan. Changes in the particle size can be detected on basis of the back-scattering signal in the middle zone of the vial [86]. If the particles grow with time due to agglomeration or coalescence, the number of scattering centers decreases in the middle zone of the vial, decreasing the back-scattering signal. In this study, changes in particle sizes were not observed for the measured suspensions.

In addition, coalescence was monitored via the particle size distribution. The particle size was determined on day $0,1,2,7$, and 21 by using the Mastersizer. With the mixing of the probes in the Mastersizer, agglomerates are divided; hence, agglomeration cannot be monitored (see Table S2). Examples of the obtained results are shown in the Figures S4 and S5. In accordance to these results, 
Kowalczyk and Baraniak [20] have stated that the instability of wax-in-water suspensions, which are stored at room temperature, is mainly caused by flotation. Coalescence could only occur with increasing temperature and melting wax.

\section{Conclusions}

In summary, HLB values of between 11 and 13.5 produce the lowest $d_{4,3}$, span of volume distribution and flotation rate. Molten candelilla wax emulsions are better stabilized using T2S2, and the particles are smaller than those obtained using T8S8. This can primarily be explained by the viscosity and chemical compatibility and their effects on particle size distributions. Coalescence and agglomeration are not observed during the storage time.

With respect to the testing methods, straightforward methods seem to be easier to interpret, compared with derived values such as ESI or TSI. The determination of the ESI after the end of flotation is thought to be futile for the observation of particle size effects. Similarly, the TSI considers various effects, making it difficult to assign single parameters.

These results help to explain, to understand, and thus to avoid instability phenomena, which are-at first sight-in contradiction to known explanations. Thus, industry and research has the chance to further enhance emulsion stability, while simultaneously decreasing e.g., the amounts and costs for emulsifiers.

Typically, different diameter types, such as $d_{1,0}, d_{3,2}$, and $d_{4,3}$ must be examined, as they reveal considerable information about the observed processes. Unfortunately, publications often do not include information about the diameter type that is being evaluated. As part of our future studies, it would be interesting to explain the impact of surfactant chemistry on the particle sphericity.

Supplementary Materials: The following are available online at http:/ / www.mdpi.com/2079-6412/8/12/469/s1, Figure S1: Extrapolation of data points from literature in combination with a purely geometrical model; Figure S2: Exemplary measurement result of the phase separation of candelilla wax-in-water suspensions, determined using Turbiscan Lab; Figure S3: Chromatogram of candelilla wax composition, obtained using gas chromatography; Figure S4: Changes in $d_{4,3}$ over storage time of candelilla wax-in-water suspensions with different HLBs of the emulsifier system; Figure S5: Changes in $d_{3,2}$ over storage time of candelilla wax-in-water suspensions with different HLBs of the emulsifier system; Table S1: Fractions of candelilla wax according to various sources; Table S2: Results of the Spearman's correlation test. The correlation between the HLB value and the change in the particle size $\left(d_{1,0}, d_{3,2}, d_{4,3}\right)$ over storage time was examined. Positive correlation $(p<0.05$, Spearman's rank correlation coefficient $>0)$ is marked by " + ", negative correlation $(p<0.05$, Spearman's rank correlation coefficient $<0)$ is marked by "-", no significant correlation is marked by " 0 " $(p>0.05)$.

Author Contributions: Conceptualization, M.L.; Methodology, M.L. and M.B.; Formal Analysis, M.B.; Investigation, M.B.; Resources, M.L. and A.S.; Data Curation, M.L. and M.B.; Writing-Original Draft Preparation, M.L. and M.B.; Writing-Review and Editing, A.S.; Visualization, M.B.; Supervision, M.L.; Project Administration, A.S.; Funding Acquisition, A.S.

Funding: This research was funded by European Commission within the Seventh Framework Program (Bio4MAP, No. 606144).

Conflicts of Interest: The authors declare no conflict of interest.

\section{References}

1. Köhler, K.; Hensel, A.; Kraut, M.; Schuchmann, H.P. Melt emulsification-Is there a chance to produce particles without additives? Particuology 2011, 9, 506-509. [CrossRef]

2. Shah, M.R.; Imran, M.; Ullah, S. Lipid-Based Nanocarriers for Drug Delivery and Diagnosis, 1st ed.; Elsevier Science: Oxford, UK, 2017.

3. Chen, C.-H.; Kuo, W.-S.; Lai, L.-S. Effect of surfactants on water barrier and physical properties of tapioca starch/decolorized hsian-tsao leaf gum films. Food Hydrocoll. 2009, 23, 714-721. [CrossRef]

4. Zhong, Q.-P.; Xia, W.-S. Physicochemical properties of edible and preservative films from chitosan/cassava starch/gelatin blend plasticized with glycerol. Food Technol. Biotechnol. 2008, 46, 262-269.

5. Sun, Q.; Sun, C.; Xiong, L. Mechanical, barrier and morphological properties of pea starch and peanut protein isolate blend films. Carbohyd. Polym. 2013, 98, 630-637. [CrossRef] [PubMed] 
6. Petersson, M.; Stading, M. Water vapour permeability and mechanical properties of mixed starchmonoglyceride films and effect of film forming conditions. Food Hydrocoll. 2005, 19, 123-132. [CrossRef]

7. Kim, K.W.; Ko, C.J.; Park, H.J. Mechanical properties, water vapor permeabilities and solubilities of highly carboxymethylated starch-based edible films. J. Food Sci. 2002, 67, 218-222. [CrossRef]

8. Botrel, D.A.; Ferreira Soares, N.F.; Camilloto, G.P.; de Barros Fernandes, R.V. Starch-based edible coating on extending shelf life of fresh-cut pear. Cienc. Rural 2010, 40, 1814-1820. [CrossRef]

9. Al-Hassan, A.A.; Norziah, M.H. Starch-gelatin edible films: Water vapor permeability and mechanical properties as affected by plasticizers. Food Hydrocoll. 2012, 26, 108-117. [CrossRef]

10. Ustunol, Z.; Mert, B. Water solubility, mechanical, barrier, and thermal properties of cross-linked whey protein isolate-based films. J. Food Sci. 2004, 69, 129-133. [CrossRef]

11. Schmid, M.; Dallmann, K.; Bugnicourt, E.; Cordoni, D.; Wild, F.; Lazzeri, A.; Noller, K. Properties of whey-protein-coated films and laminates as novel recyclable food packaging materials with excellent barrier properties. Int. J. Polym. Sci. 2012, 5, 1-7. [CrossRef]

12. Schmid, M.; Cinelli, P.; Wildner, J.; Bazzichi, A.; Lazzeri, A. Whey protein based barrier layers to enhance the barrier properties in polylactic acid films while maintaining biodegradability. In Proceedings of the International Conference on Bio-Based Polymers and Composites (BiPoCo), Siofok, Hungary, 27-31 May 2012.

13. Sabato, S.F.; Ouattara, B.; Yu, H.; D'Aprano, G.; Le Tien, C.; Mateescu, M.A.; Lacroix, M. Mechanical and barrier properties of cross-linked soy and whey protein based films. J. Agric. Food Chem. 2001, 49, 1397-1403. [CrossRef] [PubMed]

14. Mei, Y.; Zhao, Y.Y. Barrier and mechanical properties of milk protein-based edible films containing nutraceuticals. J. Agric. Food Chem. 2003, 51, 1914-1918. [CrossRef] [PubMed]

15. Tharanathan, R.N. Biodegradable films and composite coatings: Past, present and future. Trends Food Sci. Technol. 2003, 14, 71-78. [CrossRef]

16. Bourtoom, T. Edible films and coatings: Characteristics and properties. Int. Food Res. J. 2008, 15, $237-248$.

17. Nandane, A.S.; Jain, R. Value addition of fruits and vegetables by edible packaging: Scope and constraints. In Proceedings of the National Symposium on Emerging Innovative Technologies for Assurance of Quality and Safety in Processed Food, Kharagpur, India, 24-25 February 2011.

18. Morillon, V.; Debeaufort, F.; Blond, G.; Capelle, M.; Voilley, A. Factors affecting the moisture permeability of lipid-based edible films: A review. Crit. Rev. Food Sci. Nutr. 2002, 42, 67-89. [CrossRef] [PubMed]

19. Khwaldia, K.; Arab-Tehrany, E.; Desobry, S. Biopolymer coatings on paper packaging materials. Compr. Rev. Food Sci. Food Saf. 2010, 9, 82-91. [CrossRef]

20. Kowalczyk, D.; Baraniak, B. Effect of candelilla wax on functional properties of biopolymer emulsion films-A comparative study. Food Hydrocoll. 2014, 41, 195-209. [CrossRef]

21. Brock, T.; Groteklaes, M.; Mischke, P.; Strehmel, B. Lehrbuch der Lacktechnologie, 5th ed.; Vincentz Network: Hannover, Germany, 2017.

22. Müller, B.; Poth, U. Lackformulierung und Lackrezeptur, 4th ed.; Vincentz Network: Hannover, Germany, 2005.

23. Fanselow, S.; Emamjomeh, S.E.; Wirth, K.-E.; Schmidt, J.; Peukert, W. Production of spherical wax and polyolefin microparticles by melt emulsification for additive manufacturing. Chem. Eng. Sci. 2016, 141, 282-292. [CrossRef]

24. Luckham, P.F. The physical stability of suspension concentrates with particular reference to pharmaceutical and pesticide formulations. Pestic. Sci. 1989, 25, 25-34. [CrossRef]

25. Al-Sabagh, A.M.; Zaki, N.N.; Badawi, A.-F.M. Effect of binary surfactant mixtures on the stability of asphalt emulsions. J. Chem. Technol. Biotechnol. 1997, 69, 350-356. [CrossRef]

26. Liu, J.; Huang, X.-F.; Lu, L.-J.; Li, M.-X.; Xu, J.-C.; Deng, H.-P. Turbiscan lab ${ }^{\circledR}$ expert analysis of the biological demulsification of a water-in-oil emulsion by two biodemulsifiers. J. Hazard. Mater. 2011, 190, $214-221$. [CrossRef] [PubMed]

27. Califano, F.; James, N. Effects of viscosity on phase separation of liquid mixtures with a critical point of miscibility. J. Eng. Technol. Res. 2013, 5, 79-86. [CrossRef]

28. Holmberg, K. Surfactants and Polymers in Aqueous Solution, 2nd ed.; John Wiley \& Sons, Ltd.: Chichester, UK, 2003.

29. Griffin, W.C. Classification of surface-active agents by "HLB". J. Soc. Cosmet. Chem. 1949, 1, 311-326. 
30. Rowe, E.L. Effect of emulsifier concentration and type on the particle size distribution of emulsions. J. Pharm. Sci. 1965, 54, 260-264. [CrossRef] [PubMed]

31. The HLB System: A Time-Saving Guide to Emulsifier Selection, 2nd ed.; ICI Americas, Inc.: Wilmington, NC, USA, 1984.

32. Wan, L.S.C.; Heng, P.W.S.; Chan, L.W. Influence of hydrophile-lipophile balance on alginate microspheres. Int. J. Pharm. 1993, 95, 77-83. [CrossRef]

33. Al-Sabagh, A.M. The relevance HLB of surfactants on the stability of asphalt emulsion. Colloids Surf. A 2002, 204, 73-83. [CrossRef]

34. Schubert, M.A.; Müller-Goymann, C.C. Characterisation of surface-modified solid lipid nanoparticles (SLN): Influence of lecithin and nonionic emulsifier. Eur. J. Pharm. Biopharm. 2005, 61, 77-86. [CrossRef] [PubMed]

35. Qian, C.; McClements, D.J. Formation of nanoemulsions stabilized by model food-grade emulsifiers using high-pressure homogenization: Factors affecting particle size. Food Hydrocoll. 2011, 25, 1000-1008. [CrossRef]

36. Kim, K.; Voorhees, P.W. Ostwald ripening of spheroidal particles in multicomponent alloys. Acta Mater. 2018, 152, 327-337. [CrossRef]

37. Campos, A.; Gómez, C.M.; García, R.; Figueruelo, J.E.; Soria, V. Extension of the flory-huggins theory to study incompatible polymer blends in solution from phase separation data. Polymer 1996, 37, 3361-3372. [CrossRef]

38. Hou, B.; Chen, W.; Cao, Z. A process for the preparation of emulsified wax. Petrol Sci. Technol. 2007, 25, 1549-1555. [CrossRef]

39. Chen, G.; Tao, D. An experimental study of stability of oil-water emulsion. Fuel Process. Technol. 2005, 86, 499-508. [CrossRef]

40. Euston, S.R.; Hirst, R.L. Comparison of the concentration-dependent emulsifying properties of protein products containing aggregated and non-aggregated milk protein. Int. Dairy J. 1999, 9, 693-701. [CrossRef]

41. Li, C.; Liu, Q.; Mei, Z.; Wang, J.; Xu, J.; Sun, D. Pickering emulsions stabilized by paraffin wax and laponite clay particles. J. Colloid Interface Sci. 2009, 336, 314-321. [CrossRef] [PubMed]

42. Milanovic, J.; Levic, S.; Manojlovic, V.; Nedovic, V.; Bugarski, B. Carnauba wax microparticles produced by melt dispersion technique. Chem. Pap. 2011, 65, 213-220. [CrossRef]

43. Kheradmandnia, S.; Vasheghani-Farahani, E.; Nosrati, M.; Atyabi, F. Preparation and characterization of ketoprofen-loaded solid lipid nanoparticles made from beeswax and carnauba wax. Nanomedicine 2010, 6 , 753-759. [CrossRef] [PubMed]

44. Asumadu-Mensah, A.; Smith, K.W.; Ribeiro, H.S. Solid lipid dispersions: Potential delivery system for functional ingredients in foods. J. Food Sci. 2013, 78, 1000-1008. [CrossRef] [PubMed]

45. Bosquez-Molina, E.; Guerrero-Legarreta, I.; Vernon-Carter, E. Moisture barrier properties and morphology of mesquite gum-candelilla wax based edible emulsion coatings. Food Res. Int. 2003, 36, 885-893. [CrossRef]

46. Chanamai, R.; McClements, D.J. Dependence of creaming and rheology of monodisperse oil-in-water emulsions on droplet size and concentration. Colloids Surf. A 2000, 172, 79-86. [CrossRef]

47. Stokes, G.G. Mathematical and Physical Papers. Volumes I-V; Cambridge University Press: Cambridge, UK, 1901.

48. Lemarchand, C.; Couvreur, P.; Vauthier, C.; Costantini, D.; Gref, R. Study of emulsion stabilization by graft copolymers using the optical analyzer Turbiscan. Int. J. Pharm. 2003, 254, 77-82. [CrossRef]

49. Mengual, O.; Meunier, G.; Cayré, I.; Puech, K.; Snabre, P. TURBISCAN MA 2000: Multiple light scattering measurement for concentrated emulsion and suspension instability analysis. Talanta 1999, 50, 445-456. [CrossRef]

50. Mengual, O.; Meunier, G.; Cayre, I.; Puech, K.; Snabre, P. Characterisation of instability of concentrated dispersions by a new optical analyser: The turbiscan MA 1000. Colloids Surf. A 1999, 152, 111-123. [CrossRef]

51. Buron, H.; Mengual, O.; Meunier, G.; Cayré, I.; Snabre, P. Optical characterization of concentrated dispersions: Applications to laboratory analyses and on-line process monitoring and control. Polym. Int. 2004, 53, 1205-1209. [CrossRef]

52. Kim, H.-S.; Park, W.-I.; Kang, M.; Jin, H.-J. Multiple light scattering measurement and stability analysis of aqueous carbon nanotube dispersions. J. Phys. Chem. Solids 2008, 69, 1209-1212. [CrossRef]

53. Azema, N. Sedimentation behaviour study by three optical methods-Granulometric and electrophoresis measurements, dispersion optical analyser. Powder Technol. 2006, 165, 133-139. [CrossRef] 
54. Vie, R.; Azema, N.; Quantin, J.C.; Touraud, E.; Fouletier, M. Study of suspension settling: A approach to determine suspension classification and particle interactions. Colloid Surf. A 2007, 298, 192-200. [CrossRef]

55. Mirhosseini, H.; Tan, C.P.; Aghlara, A.; Hamid, N.S.A.; Yusof, S.; Chern, B.H. Influence of pectin and CMC on physical stability, turbidity loss rate, cloudiness and flavor release of orange beverage emulsion during storage. Carbohyd. Polym. 2008, 73, 83-91. [CrossRef]

56. Xu, R.L. Particle Characterization: Light Scattering Methods; Springer: Dordrecht, The Netherlands, 2000.

57. Alderliesten, M. Mean particle diameters. Part I: Evaluation of definition systems. Part. Part. Syst. Charact. 1990, 7, 233-241. [CrossRef]

58. Wooster, T.J.; Golding, M.; Sanguansri, P. Impact of oil type on nanoemulsion formation and Ostwald ripening stability. Langmuir 2008, 24, 12758-12765. [CrossRef] [PubMed]

59. Köhler, K.; Schuchmann, H.P. Emulgiertechnik: Grundlagen, Verfahren und Anwendungen; Behr's Verlag: Hamburg, Germany, 2012.

60. Malvern Mastersizer "Getting Started" Manual; Malvern Instruments: Worcestershire, UK, 1997. Available online: http:/ / pmbrc.org/index.php/download_file/view/190/ (accessed on 21 November 2018).

61. Blanshard, J.M.V.; Mitchell, J.R. Food Structure: Its Creation and Evaluation; Butterworth-Heinemann: Oxford, UK, 1988.

62. Müller, W. Mechanische Grundoperationen und ihre Gesetzmäßigkeiten, 2nd ed.; Oldenburg Wissenschaftsverlag: München, Germany, 2014; p. 316.

63. Tiller, F.M.; Yeh, C.S.; Leu, W.F. Compressibility of paniculate structures in relation to thickening, filtration, and expression-A review. Sep. Sci. Technol. 1987, 22, 1037-1063. [CrossRef]

64. Batchelor, G.K. Sedimentation in a dilute dispersion of spheres. J. Fluid Mech. 1972, 52, 245-268. [CrossRef]

65. Barnea, E.; Mizrahi, J. A generalized approach to the fluid dynamics of particulate systems. Chem. Eng. J. 1973, 5, 171-189. [CrossRef]

66. Richardson, J.F.; Zaki, W.N. Sedimentation and fluidisation: Part I. Chem. Eng. Res. Des. 1997, 75, 82-99. [CrossRef]

67. Xu, W.; Nikolov, A.; Wasan, D.T. The effect of many-body interactions on the sedimentation of monodisperse particle dispersions. J. Colloid Interface Sci. 1998, 197, 160-169. [CrossRef] [PubMed]

68. Salas, G.E.S. Sedimentationsverhalten von Submikrometerpartikeln in wässrigen Suspensionen. Ph.D. Thesis, Technical University of Dresden, Dresden, Germany, 2007.

69. Swarbrick, J.; Rubino, J.T.; Rubino, O.P. Coarse Dispersions. In Remington: The Science and Practice of Pharmacy; Troy, D., Ed.; Lippincott Williams \& Wilkins: Philadelphia, PA, USA, 2006; p. 332.

70. Mitsui, T. New Cosmetic Science; Elsevier Science: Amsterdam, The Netherlands, 1998.

71. Kim, E.-H.; Cho, W.-G. Candelilla wax nanoemulsions prepared by phase inversion composition (PIC) method. J. Oil Appl. Sci. 2014, 31, 203-209. [CrossRef]

72. Pasquali, R.C.; Taurozzi, M.P.; Bregni, C. Some considerations about the hydrophilic-lipophilic balance system. Int. J. Pharm. 2008, 356, 44-51. [CrossRef] [PubMed]

73. Wagner, W.; Kretzschmar, H.-J. Wasser. VDI-Wärmeatlas, 11th ed.; Springer: Berlin/Heidelberg, Germany, 2013; p. 189.

74. Ohba, N. Hydrophile-lipophile balance values for $\mathrm{O} / \mathrm{W}$ emulsions stabilized by nonionic surfactants. II. "Required hydrophile-lipophile balance values" of the oil mixture. Bull. Chem. Soc. Jpn. 1962, 35, 1021-1025. [CrossRef]

75. Tulloch, A.P. Comparison of some commercial waxes by gas liquid chromatography. J. Am. Oil Chem. Soc. 1973, 50, 367-371. [CrossRef]

76. Scora, G.A.; Ahmed, M.; Scora, R.W. Epicuticular hydrocarbons of candelilla (euphorbia antisiphylitica) from three different geographical areas. Ind. Crop. Prod. 1995, 4, 179-184. [CrossRef]

77. Toro-Vazquez, J.F.; Morales-Rueda, J.A.; Dibildox-Alvarado, E.; Charó-Alonso, M.; Alonzo-Macias, M.; González-Chávez, M.M. Thermal and textural properties of organogels developed by candelilla wax in safflower oil. J. Am. Oil Chem. Soc. 2007, 84, 989-1000. [CrossRef]

78. Regert, M.; Langlois, J.; Colinart, S. Characterisation of wax works of art by gas chromatographic procedures. J. Chrom. A 2005, 1091, 124-136. [CrossRef]

79. Holloway, P.J. Chemistry of leaf waxes in relation to wetting. J. Sci. Food Agr. 1969, 20, 124-128. [CrossRef]

80. Damodaran, S.; Parkin, K.L.; Fennema, O.R. Fennema's Food Chemistry, 4th ed.; CRC Press: Boca Raton, FL, USA, 2008. 
81. Sjoblom, J. Encyclopedic Handbook of Emulsion Technology; Marcel Dekker Inc.: New York, NY, USA, 2001.

82. Balzer, D.; Lüders, H. Nonionic Surfactants: Alkyl Polyglucosides; Marcel Dekker Inc.: New York, NY, USA, 2000.

83. Gao, X.; Gao, F.; Chen, L.; Yao, Y.; Chen, T.; Lin, S. Tuning the morphology of amphiphilic copolymer aggregates by compound emulsifier via emulsion-solvent evaporation. J. Saudi Chem. Soc. 2016, 22, 297-306. [CrossRef]

84. Parker, M.E.; Bronlund, J.E.; Mawson, A.J. Moisture sorption isotherms for paper and paperboard in food chain conditions. Packag. Technol. Sci. 2006, 19, 193-209. [CrossRef]

85. Chick, J.; Hernandez, R. Physical, thermal, and barrier characterization of casein-wax-based edible films. J. Food Sci. 2002, 67, 1073-1079. [CrossRef]

86. Device Manual Turbiscan ${ }^{\circledR}$ LAB; Formulaction: L'Union, France, 2014.

(C) 2018 by the authors. Licensee MDPI, Basel, Switzerland. This article is an open access article distributed under the terms and conditions of the Creative Commons Attribution (CC BY) license (http:/ / creativecommons.org/licenses/by/4.0/). 